\title{
Effect of Replicate Design on Drug Variability and Bioequivalence in Humans
}

\author{
Naji M. Najib ${ }^{1}$, Isam Salem ${ }^{1}$ and Nasir M. Idkaidek ${ }^{2 \star}$
}

${ }^{1}$ International Pharmaceutical Research Center (IPRC), Amman, JORDAN

${ }^{2}$ College of Pharmacy, Petra University, Amman, JORDAN

\begin{abstract}
The purpose of this study is to investigate the effect of using replicate design on the intra/inter subject variability and bioequivalence of drugs in healthy volunteers. Model drugs used for analysis were amoxicillin/clavulanic acid combination. 24 healthy subjects participated in this study using 4-phase replicate cross over design. Individual disposition kinetic parameters of areas under plasma concentrations $\left(\mathrm{AUC}_{0-\mathrm{t}}\right)$ and maximum concentration $\left(\mathrm{C}_{\max }\right)$ were calculated by non-compartmental analysis using Kinetica program V 4.2 using all phases. The $90 \%$ confidence intervals for log-transformed $\mathrm{AUC}_{0-\mathrm{t}}$ and $\mathrm{C}_{\max }$ were calculated for phases I \& II; then for phases I, II and III; and for phases I, II, III and IV respectively. The intra and inter-subject variability values did not show a trend to decrease by the increase in phases included in analysis in both drugs and for both parameters. In addition, the $90 \%$ confidence intervals for log-transformed $\mathrm{AUC}_{0-\mathrm{t}}$ and $\mathrm{C}_{\max }$ passed the $80-125 \%$ limit range in both drugs for all phase combinations, even though $\mathrm{C}_{\text {max }}$ variability was shown high for clavulanic acid. However, individual bioequivalence was shown for AUC and not shown for $\mathrm{C}_{\max }$ of both drugs. These results suggest not using replicate design as an approach to show the high inter/intra subject variability of highly variable drugs and hence justify wider acceptance limits of $75-133 \%$ as recommended by the draft EMEA guideline. Literature information about drug high variability should be adequate to justify using wider acceptance limits of $75-133 \%$.
\end{abstract}

Keywords: Replicate design; Acceptance limits; Bioequivalence; EMEA

\section{Introduction}

Studies to measure bioavailability and/or establish bioequivalence of a product are important elements in support of the different drug applications and their supplements (Draft Guideline on the Investigation of Bioequivalence, 2008). Of special interest are bioequivalence studies of highly variable drugs. Hence, it was recommended by the new draft EMEA guideline that $90 \%$ confidence intervals for log-transformed areas under curve for the maximum plasma concentration $\left(\mathrm{C}_{\text {max }}\right)$, to also fall between $80-125 \%$. Wider acceptance limits of $75-133$ can be justified by using replicate design to prove that drug is highly variable (Draft Guideline on the Investigation of Bioequivalence, 2008).

Statistical analysis for pharmacokinetic measures, such as area under the curve, using the standard average bioequivalence involves the calculation of a $90 \%$ confidence interval for the ratio of the averages (population geometric means) of the measures for the test and reference products. However, the average bioequivalence method does not assess a subject-by-formulation interaction variance, that is, the variation in the average test and reference difference among individuals. In contrast, the individual bioequivalence (IBE) approach assesses within-subject variability for the test and reference products, as well as the subject-by-formulation interaction (Guidance for Industry, 2001).

The purpose of this study is to investigate the effect of using replicate design on the bioequivalence of high (variability $>30 \%$ ) and low (variability $<30 \%$ ) variable drugs. Model drugs used amoxicillin/clavulanic acid combination.

\section{Materials and Methods}

Drugs

Drug formulations were amoxicillin/clavulanic acid combination.

\section{Subjects and study design}

24 healthy adult male volunteers participated in the two formulations, two sequence (TRTR, RTRT), four period cross-over single oral dose study. Sample size for each study was calculated based on reported intra-subject variability of pharmacokinetics primary parameters, considering $\alpha=0.05$, the bioequivalence range (0.8-1.25) and to obtain a statistical power greater than $80 \%$. All subjects had mean age, mean body weight and mean height. The volunteers were instructed to abstain from taking any drug including over-the counter (OTC) for 2 weeks prior to and during the study period. Studies were performed according to the revised Declaration of Helsinki for bio-medical research involving human subjects and the rules of Good Clinical Practices. Also, study protocols were approved by Institutional Review Board (IRB) of IPRC (Idkaidek, 2004).

\section{Experimental and assay procedure}

In each study, following a ten-hour overnight fast, single oral dose of each drug was administered followed by $240-\mathrm{ml}$ water

*Corresponding author: Nasir M. Idkaidek, College of Pharmacy, Petra University, Amman, JORDAN, E-mail: nidkaidek@uop.edu.jo

Received November 08, 2009; Accepted December 13, 2009; Published December 13, 2009

Citation: Najib NM, Salem I, Idkaidek NM (2009) Effect of Replicate Design on Drug Variability and Bioequivalence in Humans. J Bioanal Biomed 1: 014-016. doi:10.4172/1948-593X.1000003

Copyright: @ 2009 Najib NM, et al. This is an open-access article distributed under the terms of the Creative Commons Attribution License, which permits unrestricted use, distribution, and reproduction in any medium, provided the original author and source are credited.

J Bioanal Biomed
Volume 1(1) : 014-016 (2009) - 014 
Citation: Najib NM, Salem I, Idkaidek NM (2009) Effect of Replicate Design on Drug Variability and Bioequivalence in Humans. J Bioanal Biomed 1: 014-016. doi:10.4172/1948-593X.1000003

\begin{tabular}{|c|c|c|c|c|c|c|}
\hline Drug - Parameter & Phases & $\begin{array}{c}\text { Intra , Inter } \\
\% \mathrm{CV} \\
\end{array}$ & $\begin{array}{c}\text { Point } \\
\text { Estimate }\end{array}$ & $\begin{array}{c}\text { 90\% Lower } \\
\text { Limit } \\
\end{array}$ & $\begin{array}{c}\text { 90\% Upper } \\
\text { Limit }\end{array}$ & $\begin{array}{c}\text { BE } \\
\text { Conclusion }\end{array}$ \\
\hline Amoxicillin- AUC & I \& II & $\begin{array}{l}5.8 \\
18.7\end{array}$ & 97 & 94 & 101 & Pass \\
\hline Amoxicillin- $C_{\max }$ & I \& II & $19.1,27.9$ & 89 & 81 & 99 & Pass \\
\hline Amoxicillin- $\mathbf{A} U \mathbf{C}_{t}$ & I, II \& III & $\begin{array}{l}9.8 \\
19.3\end{array}$ & 95 & 89 & 101 & Pass \\
\hline Amoxicillin- $C_{\max }$ & I, II \& III & $22.2,29.8$ & 95 & 86 & 105 & Pass \\
\hline Amoxicillin- AUC & I, II, III \& IV & $\begin{array}{l}9.3 \\
19.2\end{array}$ & 96 & 92 & 100 & Pass \\
\hline Amoxicillin- $C_{\max }$ & I, II, III \& IV & $\begin{array}{l}21.2 \\
28.8\end{array}$ & 92 & 84 & 99 & Pass \\
\hline Clavulanic a- $\mathbf{A U C} \mathbf{C}_{t}$ & I \& II & $\begin{array}{l}16.3 \\
28.9\end{array}$ & 92 & 82 & 102 & Pass \\
\hline Clavulanic a- $\mathbf{C}_{\max }$ & I \& II & $\begin{array}{l}19.1 \\
31.6\end{array}$ & 94 & 84 & 106 & Pass \\
\hline Clavulanic a- $\mathbf{A} \mathbf{U} \mathbf{C}_{t}$ & I, II \& III & $\begin{array}{l}22.1 \\
29.4\end{array}$ & 101 & 92 & 110 & Pass \\
\hline Clavulanic a- $C_{\max }$ & I, II \& III & $\begin{array}{l}24.4 \\
31.8\end{array}$ & 100 & 88 & 114 & Pass \\
\hline Clavulanic a- AUCt & I, II, III \& IV & $\begin{array}{l}19.9 \\
27.9\end{array}$ & 96 & 89 & 104 & Pass \\
\hline Clavulanic a- $C_{\max }$ & I, II, III \& IV & $\begin{array}{l}22.7 \\
30.6\end{array}$ & 97 & 88 & 108 & Pass \\
\hline Amoxicillin- AUC ${ }_{t}$ & IBE* & \multicolumn{5}{|c|}{$\mathrm{H}_{\eta 1}=-0.081$ (Pass) } \\
\hline Amoxicillin- $\mathrm{C}_{\max }$ & IBE* & \multicolumn{5}{|c|}{$\mathrm{H}_{\eta 1}=0.019($ Fail $)$} \\
\hline Clavulanic a- $\mathbf{A U C} \mathbf{C}_{t}$ & $\mathrm{IBE}^{*}$ & \multicolumn{5}{|c|}{$\mathrm{H}_{\eta 1}=-0.0234$ (Pass) } \\
\hline Clavulanic a- $\mathbf{C}_{\max }$ & $\mathrm{IBE}^{*}$ & \multicolumn{5}{|c|}{$\mathrm{H}_{\eta 1}=0.0517$ (Fail) } \\
\hline
\end{tabular}

*IBE: Individual Bioequivalence analysis results, from reference 2.

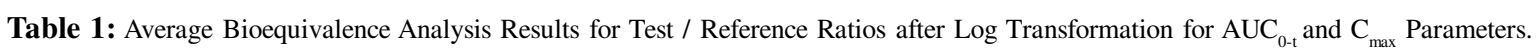

in each study. Blood samples were collected up to 10 hour after dosing. Samples were stored at $-200 \mathrm{C}$ until parent drugs are analyzed by validated and sensitive hplc method (Idkaidek, 2004).

\section{Data analysis}

Areas under plasma concentrations $\left(\mathrm{AUC}_{0-\mathrm{t}}\right)$, maximum concentration $\left(\mathrm{C}_{\max }\right)$, time to reach maximum were calculated by non-compartmental analysis for all subjects. Confidence intervals, point estimates and parameter variability analysis for logtransformed $\mathrm{AUC}_{0-\mathrm{t}}$ and $\mathrm{C}_{\max }$ were also calculated for phases I \& II; then for phases I, II and III; and for phases I, II, III and IV using Excel and Kinetica ${ }^{\circledR}$ software (Kinetica V 4.2, 2007).

\section{Results and Discussion}

Average bioequivalence analysis and IBE results were summarized in Table 1 . As shown in table 1, the $90 \%$ confidence intervals for log-transformed $\mathrm{AUC}_{0-\mathrm{t}}$ and $\mathrm{C}_{\max }$ were calculated for phases I \& II; then for phases I, II and III; and then phases I, II, III and IV respectively. The intra and inter-subject variability values did not show a trend to decrease by the increase in phases included in analysis in both drugs and for both parameters. In addition, the $90 \%$ confidence intervals for log-transformed $\mathrm{AUC}_{0-\mathrm{t}}$ and $\mathrm{C}_{\max }$ passed the 80-125\% limit range in both drugs for all phase combinations, even though Cmax variability was shown high for clavulanic acid. Thus use of replicate design did not add advantages in terms of decreasing inter/intra subject variability and also for bioequivalence limits.
However, individual bioequivalence was shown for AUC and not shown for $\mathrm{C}_{\max }$ of both high and low variable drugs (Idkaidek, 2004). This rendered the IBE approach and the replicate design unsuitable for showing formulation differences. Instead, scaled average bioequivalence of $2 \mathrm{X} 2$ cross over design would be more appropriate (WHO Guideline, 2005; Midha, 2005). Actually, US FDA guideline recommends using average cross over design, as a default design for bioequivalence studies (Guidance for Industry, 2003).

\section{Conclusion}

These results suggest not using replicate design as an approach to show the high inter/intra subject variability of highly variable drugs and hence justify wider acceptance limits of $75-133 \%$ as recommended by the draft EMEA guideline. Literature information about drug high variability should be adequate to justify using wider acceptance limits of $75-133 \%$.

\section{References}

1. Draft Guideline on the Investigation of Bioequivalence (2008) Doc. Ref. CPMP/EWP/QWP/1401/98 Rev. 1. London. » CrossRef »PubMed » Google Scholar

2. Guidance for Industry (2001) Statistical Approaches to Establishing Bioequivalence. Population and Individual Bioequivalence Working Group of the Biopharmaceutics Coordinating Committee in the Office of Pharmaceutical Science, Center for Drug Evaluation and Research (CDER) at the Food and Drug Administration (FDA). » CrossRef » PubMed » Google Scholar

3. Guidance for Industry (2003) BA and BE Studies for orally administered drug products - General Considerations. Center for Drug Evaluation and Research (CDER), Food and Drug Administration (US FDA). » CrossRef » PubMed » Google Scholar
Volume 1(1) : 014-016 (2009) - 015 


\section{Journal of Bioanalysis \& Biomedicine - Open Access \\ JBABM/Vol.1 Issue 1}

4. Idkaidek N, Alghazawi A, Najib N (2004) Bioequivalence assessment of Amoxicillin/Clavulanic acid 250/125 mg combination tabs in Healthy $\mathrm{Hu}-$ man Volunteers: Use of replicate design. Biopharmaceutics and Drug Disposition 25: 367-372. »CrossRef » PubMed » Google Scholar

5. Kinetica V 4.2, (2007) Innaphase Corp., France. » CrossRef » PubMed » Google Scholar

6. Midha K, Rawson M, Hubbard J (2005) The bioequivalence of highly vari- able drugs and drug products. Int J Clin Pharmacol Ther 43: 485-498. »CrossRef » PubMed » Google Scholar

7. WHO Guideline (2005) Multisource (GENERIC) Pharmaceutical Products: Guidelines on Registration Requirements to Establish Interchangeability. Quality Assurance \& Safety: Medicines (QSM), Department of Medicines Policy and Standards (PSM), World Health Organization. » CrossRef » PubMed » Google Scholar 